Sudipta Pal, MS'

Sampurna Pati, MBBS

Somnath Saha, MS'

Vedula Padmini Saha, MS, MCh²

'Department of ENT, Head \& Neck Surgery $R G$ Kar Medical College, Kolkata, India ${ }^{2}$ Department of Plastic Surgery

$R$ G Kar Medical College, Kolkata, India
Correspondence: Dr. Sudipta Pal 223, Lane-3, J.C.Khan Road P.O.:-Mankundu, Dist.-Hooghly, West Bengal PIN- 712139 India

E-mail: drsudiptapal@gmail.com

Phone: +919051757391, +919231535309

Reprints will not be available from the author.

The authors declared that this represents original materia that is not being considered for publication or has not been published or accepted for publication elsewhere in full or in part, in print or electronic media; that the manuscript has been read and approved by all the authors, that the requirements for authorship have been met by each author, and that each author believes that the manuscript represents honest work.

Disclosures: The authors signed disclosures that there are no financial or other (including personal) relationships, intellectual passion, political or religious beliefs, and institutional affiliations that might lead to a conflict of interest.

\section{Carcinoma Ex Pleomorphic Adenoma in the Parapharyngeal Space}

\author{
ABSTRACT \\ Objective: To present a case of carcinoma ex pleomorphic adenoma in the parapharyngeal \\ space and discuss its management.
}

\section{Methods:}

\author{
Design: Case Report \\ Setting: Tertiary Government Teaching Hospital \\ Patient: One
}

Results: A 40-year-old male patient with dysphagia for three months and a left-sided mucosacovered oropharyngeal mass was found to have a prestyloid parapharyngeal lesion on CT scans. Fine Needle Aspiration Cytology (FNAC) revealed a pleomorphic adenoma. With a past history of parapharyngeal pleomorphic adenoma excised transorally three years before, the present mass was excised by mandibular swing approach. Post-operative recovery was uneventful but the final histopathological report was carcinoma ex pleomorphic adenoma.

Conclusion: Malignant transformation should be suspected in recurrent salivary tumors in the parapharyngeal space. Provided there was truly no pre-existing malignant focus in the originallyexcised tumor, and that early recurrence was not due to inadequate initial excision, this patient had a rare condition where the same tumor underwent malignant transformation within three years only. To the best of our knowledge, such an early transformation to malignancy of a minor salivary gland tumor of the parapharyngeal space has not been reported in the English literature.

Keywords: carcinoma ex pleomorphic adenoma, pleomorphic adenoma, carcinoma, parapharyngeal space, malignant transformation, minor salivary gland tumor, mandibular swing

Parapharyngeal tumors comprise only $0.5-1 \%$ of head-neck neoplasms. Most (70$80 \%$ ) are benign and $40-50 \%$ of them arise from salivary glands, pleomorphic adenoma being the most frequent variety. ${ }^{1}$ Though salivary gland tumors are the most common group in this location malignant mixed cell tumors are a rare variety. This type of tumor can arise de novo or in a pleomorphic adenoma. Complete excision of these malignant masses maintaining oncologically-safe margins is a challenge to the attending headneck surgeon. 


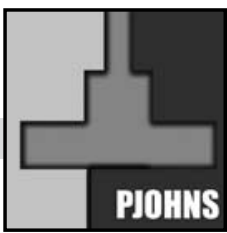

\section{CASE REPORT}

A 40-year-old male patient presented to the outpatient department with the complaint of difficulty in swallowing for the last three months. He had a past history of trans-oral surgical removal of pleomorphic adenoma of oral cavity three years back.

On examination there was fullness of the left tonsillar region and the tonsil and uvula were pushed medially to the right. (Figure 1) Intra-oral palpation revealed a firm, non-tender submucosal mass. Examination of the neck was normal.

Contrast-enhanced CT scan showed a large heterogeneously-

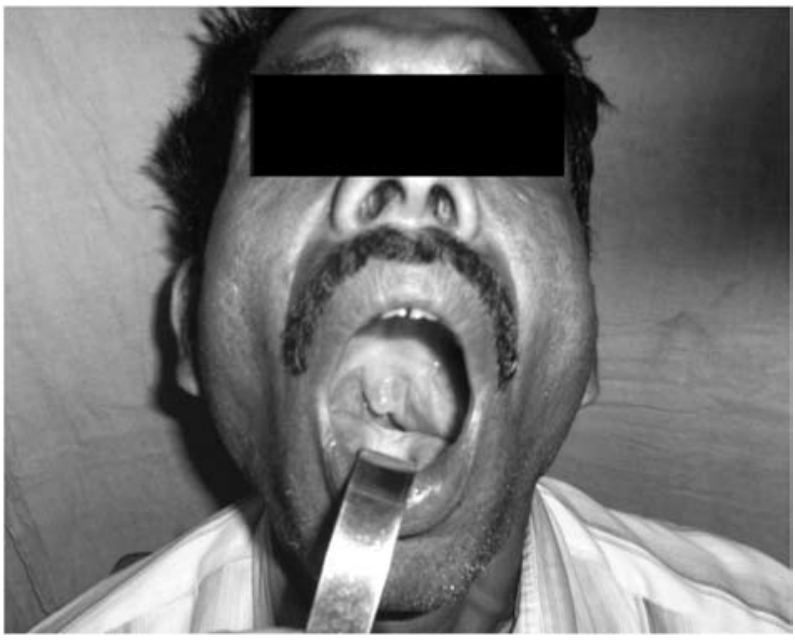

Figure 1: Clinical photograph of the patient showing the mass pushing the left tonsil medially.

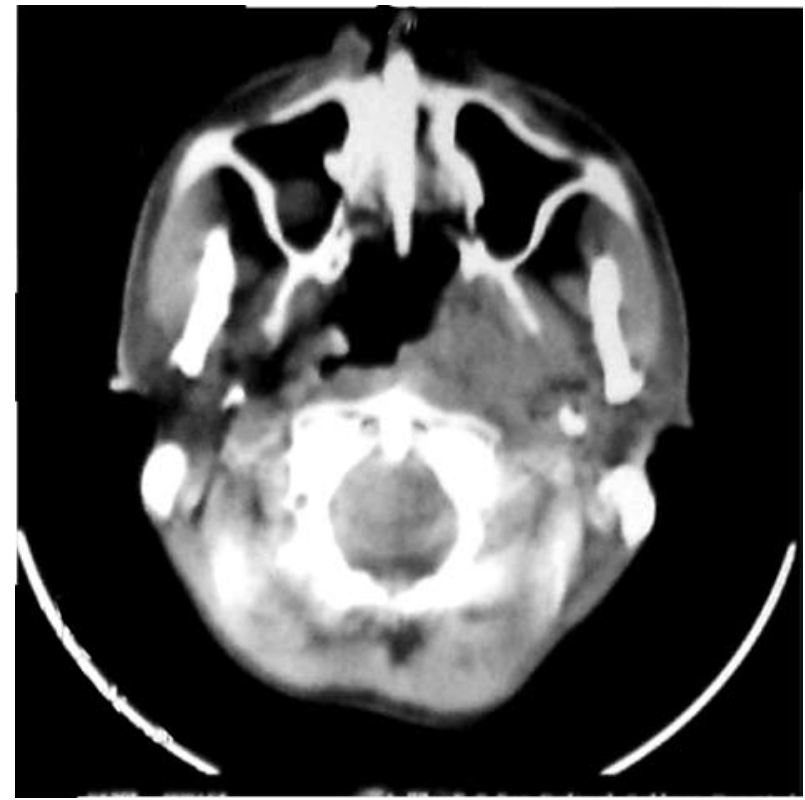

Figure 2: Contrast enhanced CT scan, axial section at the level of the second cervical vertebra showing the mass in the left parapharyngeal space near the skull base. enhancing soft tissue prestyloid mass displacing the carotid sheath posteriorly. The mass involved the entire length of the left parapharyngeal space, extending from the base of skull superiorly to the hyoid bone inferiorly and the left half of the soft palate anteriorly. (Figure 2, 3, 4) There was no evidence of bone destruction, carotid sheath or pre-vertebral space involvement.

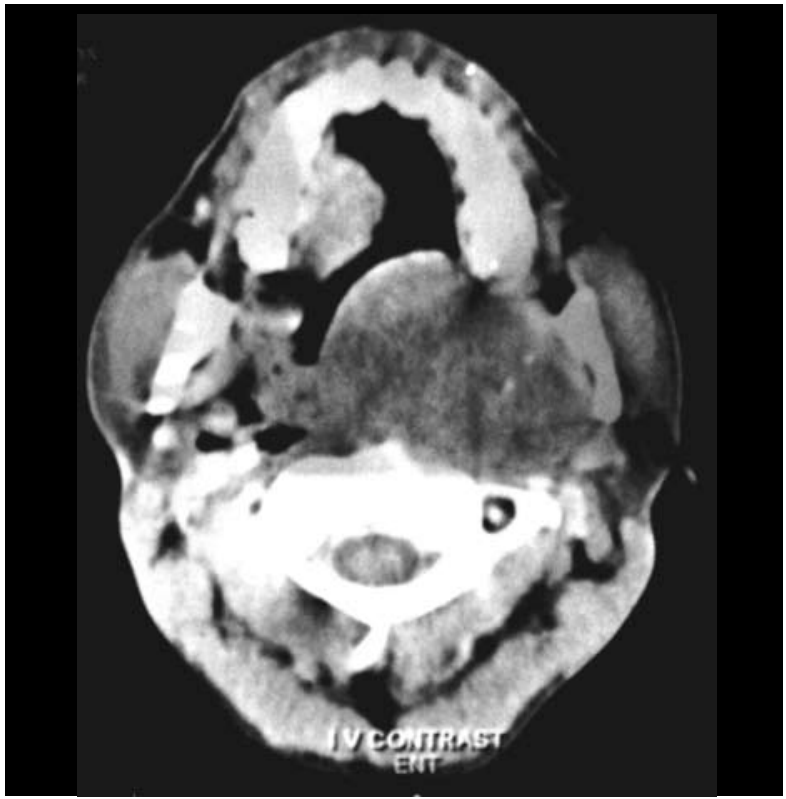

Figure 3: Contrast enhanced CT scan, axial section at the level of the third cervical vertebra showing the mass with heterogenous density and irregular uptake of contrast extending anteriorly up to the soft palate

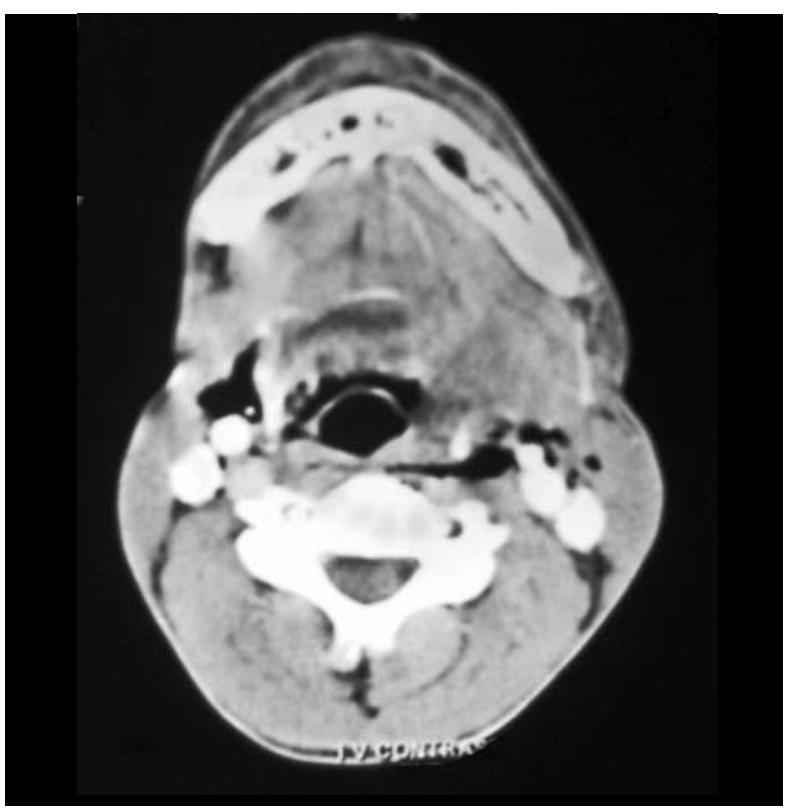

Figure 4: Contrast enhanced CT scan, axial section at the level of the fifth cervical vertebra showing the lower extent of the tumor up to the hyoid bone 
A trans-oral FNAC was suggestive of pleomorphic adenoma.

After elective tracheostomy and endotracheal intubation, the mass was excised by paramedian mandibulotomy approach followed by repair of mandible. Histology showed features of invasive carcinoma in a background of pleomorphic adenoma. (Figure 5) The carcinoma component subtype was carcinoma, not otherwise specified (NOS). (Figure 6) Capsular invasion was grossly evident during excision and microscopically confirmed. The postoperative course was uneventful and the tracheostomy tube was removed after four days. The patient received $60 \mathrm{~Gy}$ of telecobalt radiotherapy to prevent recurrence, and remained

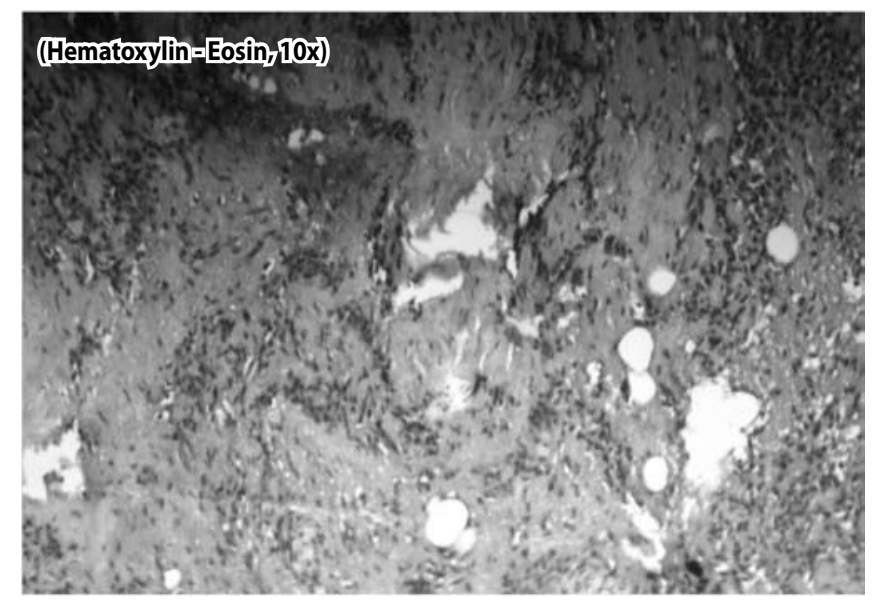

Figure 5: Histopathologic slide, Hematoxylin - Eosin in low power (10x) revealing characteristics consistent with pleomorphic adenoma. Note the presence of polygonal epithelial and spindle-shaped myoepithelial elements in a background of mucoid stroma.

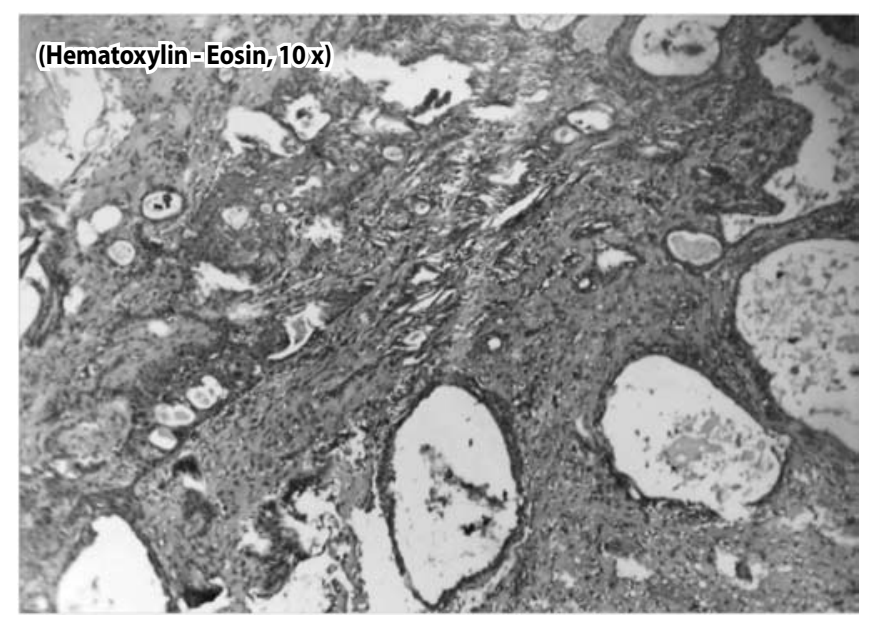

Figure 6: The same slide under a different view revealing carcinomatous components, NOS subtype.

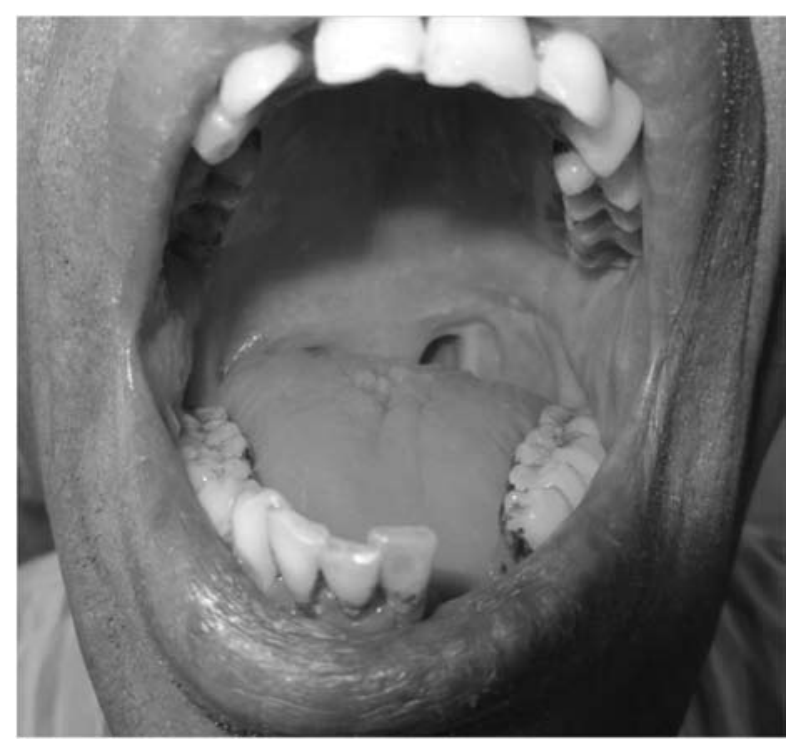

Figure 7: Post operative clinical photograph after one year

free from disease after one year of follow up. (Figure 7)

\section{DISCUSSION}

According to Youngs and Scofield, ectopic salivary tissue in the head and neck can arise from remnants of branchial apparatus and defective closure of the precervical sinus of His with internal heteroplasia., Mixed salivary tumors are the most frequent neoplasm arising from ectopic cell rests, having the same recurrence rate but much higher percentage of malignant transformation in comparison to tumors arising from major salivary glands. ${ }^{4}$ Forty to fifty percent of parapharyngeal tumors are salivary neoplasms and are commonly found in the prestyloid region. ${ }^{5}$ Among them, the pleomorphic adenoma is the most common variety. The risk of developing carcinomaex-pleomorphic adenoma from this benign tumor is $5-6 \%$ over twenty years. ${ }^{6}$ The incidence of malignant transformation depends on duration of tumor which is about $2 \%$ for tumors present less than five years and $10 \%$ for those more than 15 years. ${ }^{6}$ Peculiar in the present case is recurrence and malignant transformation within three years of primary surgery. The first operation was performed through the transoral route in which exposure of the parapharyngeal space is compromised and complete removal of tumor is very difficult. Thus, the early recurrence may be attributed to the choice of approach in the first case. However, the malignant transformation of the mass so soon is very difficult to explain and makes this case unique.

Tumors in the parapharyngeal space are challenging for clinicians with respect to early diagnosis as well as surgical resection. This is primarily due to the insidious onset of the 
lesions without any overt clinical symptom as well as the complex anatomy of the space surrounded by vital structures.

Most patients present with neck swelling (54\%) and a few with oropharyngeal swelling (10\%), as found in the present case. Other than common symptoms like dysphagia and trismus, some cases may present with cranial nerve palsy or rare symptoms like SIADH. ${ }^{7}$ Due to their deep location most of these tumors are asymptomatic till they attain a large size.

The first and most crucial step for selecting the right surgical approach is anatomical location which relies almost completely on imaging techniques. Proper exposure of parapharyngeal tumors is technically demanding. There are various approaches for the prestyloid region- transparotid, transcervial, transmandibular..$^{8-10}$ For this case the transmandibular approach was selected as it can provide maximum exposure which is essential for oncologic resection with tumor-free margins. This approach is recommended for large tumors with superior parapharyngeal space extension, vascular tumors, malignant tumors and cases where distal control of the carotid artery at the skullbase is required.

Malignant transformation in a recurrent salivary tumor is rare and commonly occurs after a long duration of around 20 years. However even early recurrence should be dealt with caution and suspicion for the presence of malignancy as evident in the present case. Provided there was truly no pre-existing malignant focus in the originally-excised tumor, and that early recurrence was not due to inadequate initial excision, this patient had a rare condition where the same tumor underwent malignant transformation within three years only. Based on a search of MEDLINE and Scopus using the keywords "ectopic salivary tumour," "recurrence," and "malignant transformation," to the best of our knowledge, such an early transformation to malignancy of a minor salivary gland tumor of the parapharyngeal space has not yet been reported in the English literature.

\section{REFERENCES}

1. Khafif A, Segev Y, Kaplan DM, Gil Z, Fliss DM. Surgical management of parapharyngeal space tumors: a 10-year review. Otolaryngol Head Neck Surg. 2005 Mar;132(3):401-6.

2. Hulburt JC. Ectopic mixed salivary tumour in the neck. J Laryngol Otol. 1978 Jun;92(6):533-6.

3. Youngs LA, Scofield HH. Heterotopic salivary gland tissue in the lower neck. Arch Pathol 1967 Jun;83(6):550-6.

4. Caironi CS, Canali RE, Canali B. Tumore misto a carcino di ghiandola salviare ectopica. (Mixed tumor carcinoma of ectopic salivary gland). Minerva Chir. 1981 May;36(9): 621-4.

5. Pang KP, Goh CH, Tan HM. Parapharyngeal space tumours: an 18 year review. J Laryngol Otol. 2002 Mar;116(3):170-5.

6. Lingen MW. Head and neck. In: Kumar V, Abbas AK, Fausto N, Aster JC, eds. Robbins and Cotran Pathologic Basis of Disease. $8^{\text {th }}$ ed. Philadelphia, PA: Saunders Elsevier, 2009. p.759

7. Jones AS. Tumours of the parapharyngeal space. In: Gleeson M, ed. Scott-Brown's Otorhinolaryngology, Head and Neck Surgery $7^{\text {th }}$ ed. Vol. 2. London: Edward Arnold, 2008. p.2529

8. Bozza F, Vigili MG, Ruscito P, Marzetti A, Marzetti F. Surgical management of parapharyngeal space tumours: results of 10-year follow-up. Acta Otorhinolaryngol Ital. 2009 Feb;29(1):10-5.

9. Gooris PJ, Worthington P, Evans JR. Mandibulotomy: a surgical approach to oral and pharyngeal lesions. Int J Oral Maxillofac Surg 1989 Dec;18(6): 359-64.

10. Aslan G, Kargi E, Görgü M, Erdoğan B, Kilinç H. Modified mandibulotomy approach to tumors of the oropharynx. Ann Plast Surg 2001 Jan; 46(1):77-9. 